\title{
Towards a new generation of sediment traps and a better measurement/understanding of settling particle flux in lakes and oceans: A hydrodynamical protocol
}

\author{
Bloesch Jürg \\ Swiss Federal Institute for Environmental Science and Technology (EAWAG) CH-8600 Düben- \\ dorf, Switzerland
}

Key words: Sediment traps, methodology, hydrodynamics, experimental calibration.

\begin{abstract}
This article is aimed at established sediment trap specialists as well as young learning scientists. The development of sediment trap techniques and hydrodynamics are briefly reviewed, with special emphasis on the experimental and in-situ trap calibration. The ongoing controversy within the trap community on the validity of flux data obtained by sediment traps can only be overcome by understanding the effects of hydrodynamics on the entrapping of settling particles in turbulent waters. A proper trap protocol is still missing. Also, the problems of entering swimmers and preservatives are not yet fully solved. Innovative ideas and robust data are needed to improve our knowledge on trapping efficiency, particle settling flux data, and the interpretation of lake and oceanic nutrient cycles. It is emphasized that controversial papers should be published when based on documented experiments and/or theory applied.
\end{abstract}

\section{Historical background of sediment trap methodology}

The desire to measure sedimentation rates of particulate material in lakes emerged at the turn of this century (Heim, 1900). At the same time, Prandtl (1904) published the boundary layer concept, which was mostly applied to moving waters. From the early days to the 1950-ies, sediment traps were simple containers without a concept of their function or preferred geometries, encompassing square boxes, jam jars, vessels and plastic bags. The goal was to just collect settling material (see review in Bloesch and Burns, 1980). There were no questions asked about the influence of turbulence and flow on the trapping efficiency. After that early stage, sediment traps have been considerably improved by two major steps.

First, sediment trap technology emanated in the early 1970-ies, when sediment traps came more and more in use. E.g., Peck (1972) tested a field sampler, originally designed for particles carried in airflow, as a sediment trap in water, stressing the similarities between the turbulent flow of air and water. The misconception that traps either act as a "snow fence", accumulating settling particulate material, or as 
a "rain gauge", was overcome later: the vertical settling velocities of particles are 1-6 orders of magnitude smaller than horizontal currents in water, whereas settling velocities of snow and rain are nearly the same as horizontal velocities of wind (Gardner, 1977; Bloesch and Burns, 1980). Gardner and Southard (1975), Gardner $(1977 ; 1980 \mathrm{a})$ and Hargrave and Burns (1979) first performed flume and settling tank experiments with sediment traps, thereby introducing the problems related to trap configuration and behaviour of moving fluid with suspended and sinking particles. In 1980, three independently published papers compiled and reviewed the existing trap literature (Bloesch and Burns, 1980; Reynolds et al., 1980; Blomqvist and Hakanson, 1981). The experiments of Gardner (1977, 1980a) with fluorescein dye and of Lau (1979) with oil droplets identified the turbulence patterns and showed in qualitative way the eddies created inside the traps. Only later, Hawley (1988) quantified the eddies with potassium permanganate dye experiments, and Gust et al. (1996) provided quantitative numbers on flushing rates. In the early 1980-ies the state-of-the-art in understanding traps was that the trap geometrical form should be a simple cylinder with an appropriate diameter $(\geq 5 \mathrm{~cm})$ and an aspect ratio (= height/diameter) $\geq 5: 1$ to ensure the best particle collection efficiency, i.e. to prevent overtrapping or undertrapping. The term efficiency refers to the "real" particle settling flux, present without a trap, which can only be measured in an experimental setup (Gardner, 1980a; Butman, 1986; Gust et al., 1996) or estimated in-situ by comparison with other methods such as scavenging of radiotracers (Buesseler, 1991; Buesseler et al., 1992, 1994, 1995; Michaels et al., 1994; Murnane et al., 1996). In agreement with Gardner (1980a), Bloesch and Burns (1980) concluded that bottle-like traps are overtrapping, while funnels are undertrapping considerably; Butman (1986) later confirmed these findings. At this time, traps were mostly used in lakes which are much less turbulent systems than are oceans.

Second, progress in trap technology was achieved by quantifying the effects of the trap internal eddies, caused by the horizontal currents approaching a trap, on the trapping efficiency. In the 1980-ies, the early sediment trap experiments of Gardner and Southard (1975), Hargrave and Burns (1979) and Gardner (1980a) were later substantiated in flume experiments by Butman (1986) and theoretically by Butman et al. (1986). Concurrent oceanic field calibration experiments were published by Gardner (1980b), Baker et al. (1988), and Gust et al. (1994). It was proposed that, apart from the trap aspect ratio and the current velocity of the approaching fluid, also the dimensionless trap Reynolds number $\operatorname{Re}_{t}=u_{f} \cdot D / v\left(u_{f}=\right.$ flow speed at the height of the trap mouth; $\mathrm{D}=$ trap mouth diameter; $v=$ fluid viscosity) is an important parameter affecting the particle trapping efficiency. Baker et al. (1988) confirmed Butman (1986) and Butman et al. (1986) that increasing current speed and trap Reynolds number as well as increasing particle settling velocity decreased relative trapping efficiency. However, the problem of an absolute measure of the in-situ flux remained elusive. The traps became a familiar instrument not only for limnologists, but also for oceanographers (e.g. MultiPIT: Knauer et al., 1979; PARFLUX MARK II: Honjo et al., 1980; Jannasch et al., 1980; VERTEX: Martin et al., 1987). Since the oceans are deficient in settling particles and require large collection areas to provide adequate particle masses during the limited period of trap deployment, the traps used in the oceans were preferably of the funnel type; 
to minimize the undertrapping of funnels baffles were installed at the top of the traps (Honjo et al., 1980; Bruland et al., 1981; Honjo and Doherty, 1988). Based on the practical and theoretical experience of Gardner $(1980 \mathrm{a}, \mathrm{b})$ and Butman $(1986$; Butman et al. 1986) baffles on top of funnels were known to damp large energetic eddies and improve trapping efficiency to a large degree dependent upon the baffle design. However, Butman (1986) pointed out that baffles increased between-replicate variability of collection efficiency. Further disadvantages of funnel type traps are the problems in defining the collection area, adhesion of particles to funnel walls and possible resuspension. In less turbulent coastal areas cylindrical traps similar to those used in lakes usually were deployed (Wassmann, 1990, 1991; Heiskanen, 1994).

Field calibration in lakes also included the measurement of resuspended bottom sediments, the secondary particulate matter flux when compared to the primary flux originating directly from the upper productive layers (Gasith, 1975). Flower (1991) used traps with a low aspect ratio and could quantify a "real" settling flux which he found to be equivalent to the natural sediment accumulation rate inferred from dated sediment cores. In this respect, bottom currents, internal seiches and boundary layers, i.e. primary causes of sediment resuspension, were studied extensively in lakes (Lemmin and Imboden, 1987; Gloor et al., 1994; Imboden and Wüest, 1995; Weyhenmeyer et al., 1995, 1996) as well as in the oceans (Caldwell and Chriss, 1979; Johnson, 1984). Substantial contributions for measuring particle export and resuspension in nepheloid layers of oceans were published e.g. by Gardner et al. (1983b), Richardson and Hollister (1987), Walsh et al. (1988), Gardner (1989), and Gardner and Richardson (1992). Reviews of sediment resuspension in combination with trap methodology have been given by Bloesch $(1994,1995)$. There was no relevant outcome for improving the existent trap protocols. The work performed, however, elucidated the origin and composition of the entrapped material, which is strongly influenced by the exposure site and depth of the traps.

The ever lasting problems of algal growth attached to the trap walls (White and Wetzel, 1973), entering swimmers (Lee et al., 1988; Karl and Knauer, 1989; Michaels et al., 1990; Hansell and Newton, 1994; Peterson and Dam, 1994; Buesseler et al., 1994; Michaels and Knap, 1996), and application of preservatives to prevent decomposition of entrapped organic matter (Gardner et al., 1983 a; Knauer et al., 1984; Karl et al., 1988; Gundersen and Wassmann, 1990; Lee et al., 1992; Hedges et al., 1993; Wakeham et al., 1993) were pursued in more detail. Petersen et al. (1993) evaluated valved sediment traps, which excluded large zooplankton by $88 \%$, on average, relative to non-valved control traps. The problems associated with the addition of brine, used to allow for a stable quiescent zone at the bottom of traps have been extensively studied by Gardner and Zhang (1996). Also, the question whether traps catch particles size- and/or density-selectively has been addressed (Blomqvist and Kofoed, 1981). The behaviour of sinking particles in eddies entering a trap is dependent on fluid drag and gravity-buoyancy, and more dense particles may spiral outwards, and larger or less dense particles may spiral inside to the orbit center (Tooby et al., 1977), thus causing undertrapping of small, dense mineral particles and overtrapping of large, light organic particles. The effects of tilting traps was discussed as a further significant bias in quantifying settling flux (Gardner, 1985). Most of these uncertainties were identified and discussed at the U.S.GOFS meeting at the University of Southern Mississippi in November 1988 (U.S.GOFS, 
1989), and the first International JGOFS Symposium in Villefranche sur Mer in May 1995 (Gardner 1996; see also IOC, 1994). All these efforts were leading to recommendations, individual evaluations, and proposed research topics on trap methodology; however, many of the swimmer and preservative issues as well as the hydrodynamic issues remain puzzling. A comprehensive compilation and comment of the existing trap techniques was also presented in Rosa et al. (1994).

A new area of trap design developed along the line of sequential or time-integrating sediment traps (Zeitzschel et al., 1978; Jannasch et al., 1980; Honjo et al., 1980) ${ }^{1}$. They basically allow for measuring short term pulses of particle mass accumulating in sediment traps; however, there is still need to improve the sample preservation techniques and to prevent malfunction of the electronical and/or mechanical rotation sampling systems. A specific problem rises with sequential funnels, since material adhering to funnel walls cannot be assigned to the single sample tubes. These sequential sediment traps have been used since to collect zooplankton in remote arctic areas (Forbes et al., 1992). Recently, Hargrave et al. (1994) developed a current-activated sediment trap that collects particles based on preselected current speed and direction criteria. Sedimentation peaks can thus be clearly related to wind and tide events. An even more interesting application of sediment traps has been suggested by Cranford and Hargrave (1994), who converted sequentially sampling traps into a BIOTRAP to conduct feeding experiments on bivalves.

\section{Trap calibration and hydrodynamics}

The problem of trap configuration appeared to be solved in the 1980-ies - for no obvious reason other than a consensus by the leading scientists based on the Gardner and Butman data and a lack of instruments to probe deeper. There was and still is no data set permitting final conclusions that traps are perfect interceptors of settling particles, despite of considerable efforts to deal with this complex issue (U.S.GOFS, 1989; IOC, 1994; Gardner 1996). However, the problem resurfaced

Presently, the following sequential sediment traps (20-24 samples) are available on the market (this list does not claim to be complete):

1. SALZGITTER sediment trap, various sizes, funnel (Salzgitter Elektronik GmbH, P.O. Box 160, D-2302 Flintbek, Germany).

2. TECHNICAP PPS sediment trap, various models, funnel (Technicap, 4 Avenue J. Abba, F-06320 Cap d'Ail, France).

3. "KIEL" SEDIMENT TRAP, various sizes, funnel (Aqua Tec Meerestechnik GmbH, Mühlenkappel 13, D-24147 Klausdorf, Germany; Markasub, Bachlettenstrasse 8, P.O. Box 112, CH-4011 Basel, Switzerland).

4. PARFLUX MARK 7G-21 time-series sediment trap, various models, funnel (McLane, Research Laboratories, Inc., 296 West Falmouth Highway, Falmouth, MA 02540, USA).

5. AQUATEC sediment trap, various sizes, funnel (Aquatec Meerestechnik GmbH, Hamburger Chaussee 25, D-24220 Flintbek, Germany).

6. HYDRO-BIOS multi sediment trap, also as single bottle version, cylinder (HYDRO-BIOS Apparatebau GmbH, Am Jägersberg 5-7, P.O.Box 8008, D-24154 Kiel-Holtenau, Germany).

7. "EADIE (1997)-Trap: 8" diameter cylindrical device with 23 , independently programmable, collection bottles (Great Lakes Engineering, Orest-Chapelsky, owner. Ann Arbor, Michigan, U.S.A. 48103). 
after intensive trap flux studies and compilation of Thorium calibration data in the oceans (e.g. Biscaye et al., 1988; Buesseler, 1991; Wei and Murray, 1992; Buesseler et al., 1992, 1994, 1995; Michaels et al., 1994; Biscaye and Anderson, 1994; Gardner, 1996: While the Thorium modeled fluxes apply only to the upper $70-200 \mathrm{~m}$, i.e. to the depth of disequilibrium in the open turbulent ocean, the Thorium scavenging method covers greater depths.) The circulation through the interior of the trap was seen to affect the behaviour of settling particles and to bias settling flux measurements in an untolerable way in strong currents, as normally found in the oceans (Johnson et al., 1991; Gust et al., 1992). Data from cylindrical traps were not compatible with fluxes derived by other methods, seemingly undertrapping significantly because of poorly understood hydrodynamic biases of the arrays (Michaels et al., 1994; Gardner 1996). On the other hand, in flume studies Gust et al. (1996) inferred that cylindrical traps over- and undertrap based on the settling velocity of the sinking particle ensemble, and that trap. Reynolds number similarly may not hold. The use of funnels, baffles and free-drifting (tethered) traps (Staresinic et al., 1982) enlarged confusion and highlighted the problem of a missing trap protocol as well. A most interesting approach of measuring vertical and horizontal particle flux by using traps with openings either on top, at the bottom and on the side walls was presented by Gardner et al. (1996); but the reason why traps with sealed lids yield flux values comparable with "normal" cylindrical traps is hydrodynamically not fully understood.

This state of affairs suggests that researchers with hydrodynamical background take a closer look at the wide scatter in flux data and their interpretation. It appears to be necessary to go back to the experimental and numerical level, to study the mechanisms of fluid and particle movement around and within traps, to evaluate current trap designs and concepts, and to develop new ones if needed, all of which should be tested in situ for the role of hydrodynamics in connection with the Thorium technique.

\section{Ethics of publishing controversial papers}

A major scientific controversy originated from the experiments of Gust et al. (1996). Specifically, their new particle seeding-technique was accused to bias their results, since these were claimed to be contradictory to the findings of Butman (1986), who used the traditional flume-seeding technique. The important question for sediment trap users is, whether Gust's findings of increased trapping efficiency with increasing horizontal flow velocity and increasing trap Reynolds number is new hydrodynamical understanding or simply an artifact. For further experimental and scientific details I refer to Gust et al. (1996), where both data sets are compared.

Controversies often evolve in science and have to be resolved not only since Galileo Galilei's famous statement that the planet earth is a globe, and not a disc. Controversy is the nucleus of either new insights or confirmation of current knowledge. The quest for a trap calibration protocol and current lack, or, alternatively, an adequate foundation for such a protocol, lies at the heart of the still unresolved issue on trap accuracy. Any opposing views should be based on evidence represented by facts, and should not degrade into a debate on who is "right" and who is "wrong" which polarizes the community into "believers" and "non-believers". 
In the specific case, a number of reviewers tried to hinder the publication of the Gust et al. (1996) paper, so as to "escape" the controversy or "solve" the problem in the sence they thought it should be solved, evidenced by one major statement of an anonymous reviewer, that such a publication with a supposedly wrong experimental design, would add more confusion to the scientific world and therefore must not be published.

Being aware of the often painful routes of scientific history, it is my deep feeling that controversies must be discussed in public, since they typically form the nucleus of progress. Many new ideas, strongly objected at first by the established scientific community, provided break-throughs at later times. It is, in my opinion, not the major question, whether a newly introduced experimental design is wrong or right; the basic question is (unless the "offending" article is obviously ignoring fundamental natural laws) that of academic rigor and style, meaning that an author is allowed to publish, to defend his results in public, to suffer self-afflicted failure or to earn the merits of new progress. Such a paper, when respecting the rules and quality standards of scientific publications, should not be judged by anonymous review. It is common, rather, and should be further encouraged, that objecting scientists (including referees) can publish their arguments in a comment paper, and the author can reply accordingly. It is subsequently up to the readers to decide which data base they should select as foundation for their own trap-related pursuit of knowledge and research.

As referee of several of the aforementioned publications, I could gain insight into this specific progress, and have managed to get the Gust et al. (1996) paper published. While scientists of the trap scene nearly unequivocally agree on the need to have a proper trap protocol, the same data sets are often interpreted differently (see e.g. Gardner and Zhang, 1996; Gardner et al., 1996). The debate who refutes whom should be discussed in the forum of scientific journals. The discrepancy in opinions and data interpretation may reflect the different ways of thinking in two disciplines. While we cannot resolve these discrepancies at present, they should provoke further research into the calibration of sediment traps and the search for an acceptable trap protocol.

\section{Particle settling flux in lakes and oceans - why a protocol?}

At this stage of the discussion, it may be necessary to provide some information on the importance of particle settling flux in lakes and oceans. It is important to realize that the striking differences of these two systems, with regard e.g. to currents as well as particle concentration, size, and physical/chemical or biological transformation, do not only reflect the different use and practice in trap methodology, but also a different direction of research and interpretation of flux data. Baines et al. (1994) have characterized the difference between lakes and oceans with regard to planktonic primary production and carbon sinking flux: the settling rates in the oceans are $2-3$ fold higher, as nutrient recycling and nature of settling material are different. While in most lakes the seasonal pattern of primary production is reflected by the flux of particulate carbon (Bloesch et al., 1977; Stabel, 1985), Karl et al. (1996) recently found a decoupling of particle production and flux in the subtropical North Pacific Ocean. 
In lakes, major topics for the use of sediment traps so far have been the phosphorus, nitrogen and carbon cycles (Bloesch et al., 1977; Gächter and Bloesch, 1985; Fukushima et al., 1989; Urban et al., 1996), heavy metal and radionuclide scavenging (Sigg, 1985; Sigg et al., 1987; Santschi, 1989; Wieland et al., 1993), settling behaviour of algae (Bloesch, 1974; Reynolds, 1984), calcite formation and aggregation triggered by diatoms (Kelts and Hsü, 1978; Stabel, 1985), and bottom sediment resuspension and sediment focusing (Davis et al., 1985; Hilton et al., 1986; Gálvez and Niell, 1992; Kozerski, 1994; Bloesch, 1995; Weyhenmeyer, 1996a, 1996b). All this work was aimed at understanding metabolism and function of specific lake ecosystems in order to find measures to solve eutrophication problems.

In oceans, main topics have been particle aggregation ("marine snow": Honjo, 1982; Asper, 1987; Alldredge and Gotschalk, 1988; Karl et al., 1988; Shanks and Edmondson, 1990), benthic food chain dynamics (Graf, 1992; Cranford and Hargrave, 1994), and trap calibration studies (as outlined above). Major importance, however, is attributed to the harassing question of new and export production (Wassmann, 1990), i.e. whether the oceans are a sink or a source of $\mathrm{CO}_{2}$ with regard to the greenhouse effect (Michaels et al., 1994). This is the reason why emotions are so high with respect to judging the precision of sediment trap data: they are crucial for establishing the uncertainties in the prognosis of our predictive models, which in turn will not only concern the scientific community, but also affect politics, and humans at large. Mass balance calculations need, by all means, to respect also other components than settling flux, such as vertical zooplankton migration, advection, and turbulent mixing (Michaels et al., 1994; Gardner, 1996).

It has been stressed for both lakes and oceans that apart from the trap calibration problems spatial and vertical in-situ differences in settling flux contribute to the variability and absolute flux. Bloesch and Burns (1980) explained that traps placed in the epilimnion of a lake tend to overtrap to an unknown and variable degree as they are subject to Langmuir circulations; and that therefore traps should not be deployed in the turbulent mixing layer. Similarly, Gardner and Richardson (1992) stated that flux cannot be accurately measured with traps when deployed in the turbulent mixed-layer of oceans that keep particles in suspension. There is growing concern about the accuracy of fluxes measured with traps in the upper ocean (Buesseler, 1991; Michaels et al., 1994). As Gardner (1996) points out other factors such as large-scale flow and related tilt and mooring dynamics may be more important than trap Reynolds numbers; also, hydrodynamic effects are particle selective and may be very different on aggregates than on solid particles such as fecal pellets. As mentioned above, traps deployed in the nepheloid layers measure both primary and secondary flux, which should not be mixed up with overtrapping. The magnitude of spatial inhomogeneity (patchiness) of settling flux is unknown for the oceans, according to Gardner (1996). Certainly, there is spatial heterogeneity, but it does not answer the question of trap accuracy. Bloesch and Burns (1980) report methodological variability of parallel traps in the same mooring, and in parallel moorings in lakes several $100 \mathrm{~m}$ apart beeing usually within $10 \%$. However, significant horizontal sedimentation differences exist over larger scales, including the pelagic and littoral (Bloesch and Uehlinger, 1986). 
Accuracy of sediment traps and other instruments or methods

It is well accepted that any results and interpretation of data should originate from a proper method. It is recognized as well that all experimental methods have an uncertainty limit or error margin, and that one should try to minimize this error at its best. For example, if I compare the potential methodological errors of sediment traps with those of the $\mathrm{O}_{2}$-method and ${ }^{14} \mathrm{C}$-technique used for measuring primary production, which is as important for the interpretation of global C-fluxes, I come to the conclusion that the latter is most probably afflicted with as many artifacts as the trap method (e.g. enclosures of algal microcosms; temperature, light and pressure shocks; UV-inhibition; extrapolation-models for daily, monthly and yearly production; etc.; for details see Vollenweider, 1974; Schwoerbel, 1994). The published primary production data show very large scattering and may include standard deviations of up to $100 \%$ under given in-situ conditions (P. Bossard, pers. communication), whereas traps exposed in less turbulent waters than open oceans yield standard deviations of less than $20 \%$ (Bloesch and Burns, 1980). However, it is not a question of discarding traps, since they are useful and there is actually no methodological alternative for studying the sinking velocity of settling particles and their behaviour, such as aggregation, adsorption and particle transformation, and to elucidate particulate matter flux in various depths of lakes and oceans. The collection of particles by centrifugal pumps (Rosa et al., 1994) may be used for specific questions, however, the artificial stress (e.g. aggregate break-up) on the particles during collection may bias the findings significantly. Also, dating techniques and balance calculations to obtain sediment accumulation rates in lakes are subject to various uncertainties (Bloesch and Evans, 1982; Dillon et al., 1990; Michaels et al., 1994).

The most crucial point, however, is to execute correct measurements and precise quantifications of the settling flux to supply numerical models with adequate input data. What then can be considered as the "correct measurement"? Since there is no absolute reference at present, we have to calibrate the settling flux measured by the current trap methods with that measured by another method, e.g. mass balance calculation and bottom sediment accumulation for lakes (Bloesch and Evans, 1982; Dillon et al., 1990), or radionuclide scavenging in oceans (e.g.: Wei and Murray, 1992; Buesseler et al., 1994; Gardner, 1996). On one hand, we have to accept the fact that a sediment trap, as any other instrument, has an instrumental error, which we have to minimize. On the other hand, all calibration methods have an error of their own. It is surprising, then, that in most trap calibration works, the reference values from other methods are considered as $100 \%$ "true", while the difference is attributed to the trap method, which is considered to measure "wrong" results. Yet, the hydrodynamic effects, where looked into with appropriate tools on-line, appear to be real and request to be addressed.

\section{Future perspectives: Towards a new sediment trap protocol}

From the preceding explanations and evaluations I conclude that a new trap protocol is necessary, as a simple state-of-the-art in understanding sediment trap per- 
formance is not possible. At present, the founded basis of further trap research is the cylinder with appropriate dimensions (diameter $\geq 5 \mathrm{~cm}$; aspect ratio $\geq 5: 1$ ). Yet apart from the old, unresolved problems of decomposition (preservatives) and entering swimmers biasing the collected material, new issues on trap non-performance emerged. For example, flow, flow entry, hydrodynamics inside traps, trap Reynolds number, trap array particulars, trap devices with sealed lids and sinking particle pool all mix up the picture from which it is impossible to obtain simply and easily the flux. As the process of particle settling in turbulent water bodies is rather complex, it is still debated, whether turbulence increases or decreases settling velocity (Bloesch and Burns, 1980). An obstacle such as a trap does not facilitate the situation for determining the true settling flux of particles. A combination of current meters and traps, as presented by Hargrave et al. (1994) and recommended by Gardner (1996), may help to elucidate the process and measurement of particle flux, especially if compared with the Thorium technique.

The progress towards a new generation of sediment traps requires three avenues. First, further hydrodynamical laboratory experiments are needed to better understand the particle collecting mechanisms and trapping efficiency. I feel that the cylinder will remain advantageous over funnels and bottles, as the collecting area is well defined and the bias by currents seems to be simpler than with more difficult geometrical designs; the baffled funnel may remain favorable in oceans because of focusing the spare particles. Second, in-vitro experimental data need to be extrapolated to in-situ conditions. Gust et al. (1996) have tried to identify the key parameters involved and (so far) have suggested an ensuing semi-empirical correction model for the in-situ flux derived from cylinders. Third, we need further innovative field calibration techniques, possibly linked with new designs of trap deployment and moorings. Neutrally buoyant drifting sediment traps have been recently introduced (Diercks and Asper, 1994). Moreover, truly free-floating platforms with traps attached, adjusting their buoyancy to compensate particle weight, are being developed and are soon ready to be tested in the field up to 400 $m$ water depth (G. Gust, pers. communication). They should provide an environment of zero slip velocity to the trap. Further recommendations are given in U.S.GOFS (1989), IOC (1994), and Gardner (1996).

In conclusion, there is only one direction to pursue: To promote further experimental, numerical and in-situ studies for trap calibration and methodological improvements, to publish controversial results in order to maintain a fruitful discussion, to stimulate scientists to perform and interpret further trap and flux studies, and to include as many as possible disciplines (such as physics and hydrodynamics) in the efforts towards more efficient trap protocols. I truly hope that this article contributes to meeting this perspective and expectation.

\section{ACKNOWLEDGEMENT}

I thank the editor-in-chief of "Aquatic Sciences", Peter Bossard, for supporting my efforts to publicly encourage the publication of controversial papers. The critical reviews of Giselher Gust and Wilford Gardner helped to improve the manuscript. 


\section{REFERENCES}

Alldredge, A.L. and C. Gotschalk, 1988. In situ settling behaviour of marine snow. Limnol. Oceanogr. 33:339-351. Asper, V.L., 1987. Measuring the flux and sinking speed of marine snow aggregates. Deep-Sea Res.
34:1-17.

Baines, S. B., M.L. Pace and D.M. Karl, 1994. Why does the relationship between sinking flux and planktonic primary production differ between lakes and oceans? Limnol. Oceanogr. 39: 213-226.

Baker, E.T., H.B. Milburn and D.A. Tennant, 1988. Field assessment of sediment trap efficiency under varying flow conditions. J. Mar. Res. 46:573-592.

Biscaye, P.E. and R.F. Anderson, 1994. Fluxes of particulate matter and on the slope of the southern Middle Atlantic Bight: SEEP-II. Deep-Sea Res. II, 41:459-509.

Biscaye, P.E., R.F. Anderson and B.L. Deck, 1988. Fluxes of particles and constituents to the eastern United States continental slope and rise: SEEP-I. Cont. Shelf Res. 8:855-904.

Bloesch, J., 1974. Sedimentation und Phosphorhaushalt im Vierwaldstättersee (Horwer Bucht) und im Rotsee. Schweiz. Z. Hydrol. 36:71-186.

Bloesch, J., 1994. A review of methods used to measure sediment resuspension. Hydrobiologia 284:13-18.

Bloesch, J., 1995. Mechanisms, measurement and importance of sediment resuspension in lakes. Mar. Freshwater Res. 46:295-304.

Bloesch, J. and N.M. Burns, 1980. A critical review of sedimentation trap technique. Schweiz. Z. Hydrol. 42:15-55.

Bloesch, J. and R.D. Evans, 1982. Lead-210 dating of sediments compared with accumulation rates estimated by natural markers and measured with sediment traps. Hydrobiologia 92:579-586.

Bloesch, J. and U. Uehlinger, 1986. Horizontal sedimentation differences in a eutrophic Swiss lake. Limnol. Oceanogr. 31:1094-1109.

Bloesch, J., P. Stadelmann and H. Bührer, 1977. Primary production, mineralization, and sedimentation in the euphotic zone of two Swiss lakes. Limnol. Oceanogr. 22:511-526.

Blomqvist, S. and L. Hakanson, 1981. A review on sediment traps in aquatic environments. Arch. Hydrobiol. 91:101-132.

Blomqvist, S. and C. Kofoed, 1981. Sediment trapping - A subaquatic in situ experiment. Limnol. Oceanogr. 26:585-590.

Bruland, K. W., R.P. Franks, W.M. Landing and A. Soutar, 1981. Southern California inner basin sediment trap calibration. Earth Planet. Sci. Letts. 53:400-408.

Buesseler, K.O., 1991. Do upper-ocean sediment traps provide an accurate record of particle flux? Nature 353:420-423.

Buesseler, K.O., M.P. Bacon, J.K. Cochran and H.D. Livingston, 1992. Carbon and nitrogen export during the JGOFS North Atlantic Bloom Experiment: estimated from ${ }^{234} \mathrm{Th}:{ }^{238} \mathrm{U}$ disequilibria. Deep-Sea Res. 39:1115-1138.

Buesseler, K.O., A.F. Michaels, D. A. Siegel and A.H. Knap, 1994. A three dimensional timedependent approach to calibrating sediment trap fluxes. Global biogeochemical cycles 8:179-193.

Buesseler, K.O., J.A. Andrews, M.C. Hartman, R. Belastock and F. Chai, 1995. Regional estimates of the export flux of particulate organic carbon derived from thorium-234 during the JGOFS WqPac program. Deep-Sea Res. 42:777-804.

Butman, Ch.A., 1986. Sediment trap biases in turbulent flows: results from a laboratory flume study. J. Mar. Res. 44:645-693.

Butman, Ch. A., W.D. Grant and K.D. Stolzenbach, 1986. Predictions of sediment trap biases in turbulent flows: a theoretical analysis based on observations from the literature. J. Mar. Res. 44:601-644.

Caldwell, D.R. and T.M. Chriss, 1979. The viscous sublayer at the sea floor. Science 205: $1131-1132$.

Cranford, P.J. and B.T. Hargrave, 1994. In situ time-series measurement of ingestion and absorption rates of suspension-feeding bivalves: Placopecten magellanicus. Limnol. Oceanogr. 39: 730-738. 
Davis, M.B., M.S. (Jesse) Ford and R.E. Moeller, 1985. Paleolimnology, Chapter VII, pp. 345-429. In: G.E. Likens (Ed.), An ecosystem approach to aquatic ecology. Mirror Lake and its environment. Springer, New York.

Diercks, A. and V. Asper, 1994. Neutrally buoyant sediment traps: The first designs. EOS, Transactions Amer. Geophys. Union 75:22.

Dillon, P.J., R.D. Evans and L.A. Molot, 1990. Retention and resuspension of phosphorus, nitrogen, and iron in a central Ontario lake. Can. J. Fish. Aquat. Sci. 47:1269-1274.

Eadie, B.J. (1997). Probing particle processes in Lake Michigan using sequencing sediment traps. Water, Air, and Soil Pollution 76, accepted.

Flower, R.J., 1991. Field calibration and performance of sediment traps in a eutrophic holomictic lake. J. Palaeolimnol. 5:175-188.

Forbes, J.R., R.W. Macdonald, E.C. Carmack, K. Iseki and M.C. O'Brien, 1992. Zooplankton retained in sequential sediment traps along the Beaufort Sea Shelf Break during winter. Can. J. Fish. Aquat. Sci. 49:663-670.

Fukushima, T., M. Aizaki and K. Muraoka, 1989. Characteristics of settling matter and its role in nutrient cycles in a deep oligotrophic lake. Hydrobiologia 176/177:279-295.

Gálvez, J.A. and F.X. Niell, 1992. Sediment resuspension in a monomictic eutrophic reservoir. Hydrobiologia 235/236:133-141.

Gächter, R. and J. Bloesch, 1985. Seasonal and vertical variation in the C: $P$ ratio of suspended and settling seston of lakes. Hydrobiologia 128:193-200.

Gardner, W.D., 1977. Fluxes, dynamics and chemistry of particulates in the ocean. Massachusetts Institute of Technology/Woods Hole Oceanographic Institution Joint Program in Oceanography, Ph.D. Dissertation. 405 pp.

Gardner, W.D., 1980a. Sediment trap dynamics and calibration. A laboratory evaluation. J. Mar. Res. 38:17-39.

Gardner, W.D., 1980b. Field assessment of sediment traps. J. Mar. Res. 38:41-52.

Gardner, W.D., 1985. The effect of tilt on sediment trap efficiency. Deap-Sea Res. 32:349361.

Gardner, W.D., 1989. Baltimore Canyon as a modern conduit of sediment to the deep sea. DeepSea Res. 36:323-358.

Gardner, W.D., 1996. Sediment trap technology and sampling in surface waters. Report on the JGOFS Symposium in Villefranche sur Mer in May, 1995.

Gardner, W.D. and J.B. Southard, 1975. Flume experiments on fine-sediment deposition in the ocean (abs.). Geol. Soc. Amer. with Programs, V. 7, p. 1083.

Gardner, W.D. and M.J. Richardson, 1992. Particle export and resuspension fluxes in the western North Atlantic. In: G.T. Rowe and V. Pariente (Eds.), Deep-Sea Food Chains and the Global Carbon Cycle, Kluwer Academic Publishers, The Netherlands, pp. 339364.

Gardner, W.D. and Y. Zhang, 1996. The effect of brine on the collection efficiency of cylindrical particle traps. Deep-Sea Research, in press.

Gardner, W.D., K.R. Hinga and J. Marra, 1983a. Observations on the degradation of biogenic material in the deep ocean with implications on accuracy of sediment trap fluxes. J. Mar. Res. 41:195-214.

Gardner, W.D., M.J. Richardson, K.R. Hinga and P.E. Biscaye, 1983b. Resuspension measured with sediment traps in a high-energy environment. Earth and Planet. Sci. Lett. 66:262278.

Gardner, W.D., P.E. Biscaye and M.J. Richardson, 1996. Sediment traps in the Vema Channel: Collectors of vertical or horizontal particulate flux? Deep-Sea Research, submitted.

Gasith, A., 1975. Tripton sedimentation in eutrophic lakes - simple correction for the resuspended matter. Verhandlungen. Internat. Verein. theoret. angew. Limnol. 19:116-122.

Gloor, M., A. Wüest and M. Münnich, 1994. Benthic boundary mixing and resuspension induced by internal seiches. Hydrobiologia 284:59-68.

Graf, G., 1992. Benthic-pelagic coupling: a benthic view. Oceanogr. Mar. Biol. Annu. Rev. 30:149-190.

Gundersen, K. and P. Wassmann, 1990. Use of chloroform in sediment traps: caution advised. Mar. Ecol. Progr. Ser. 64:187-195. 
Gust, G., R.H. Byrne, R.E. Bernstein, P.R. Betzer and W. Bowles, 1992. Particle fluxes and moving fluids: experience from synchronous trap collections in the Sargasso Sea. Deep-Sea Res. 39:1071-1083.

Gust, G., A.F. Michaels, R. Johnson, W. G. Deuser and W. Bowles, 1994. Mooring line motions and sediment trap hydromechanics: in-situ intercomparison of three common deployment designs. Deep-Sea Res. 41:831-857.

Gust, G., W. Bowles, S. Giordano and M. Hüttel, 1996. Particle accumulation in a cylindrical sediment trap under laminar and turbulent steady flow: an experimental approach. Aquatic Sci., pp. 297-326.

Hansell, D.A. and J. A. Newton, 1994. Design and evaluation of a "swimmer"-segregating particle interceptor trap. Limnol. Oceanogr. 39:1487-1495.

Hargrave, B.T. and N.M. Burns, 1979. Assessment of sediment trap collection efficiency. Limnol. Oceanogr. 24:1124-1135.

Hargrave, B.T., G. Siddall, G. Steeves and G. Awalt, 1994. A current-activated sediment trap. Limnol. Oceanogr. 39:383-390.

Hawley, N., 1988. Flow in cylindrical sediment traps. J. Great Lakes Res. 14:76-88.

Hedges, J.I., C. Lee, S. G. Wakeham, P.J. Hernes and M.L. Peterson, 1993. Effects of poisons and preservatives on the fluxes and elemental compositions of sediment trap materials. J. Mar. Res. 51:651-668.

Heim, A., 1900. Der Schlammabsatz am Grund des Vierwaldstättersees. Vjschr. naturf. Ges. Zürich 45:164-182.

Heiskanen, A.-S., 1994. Impact of dinoflagellates on the flux of organic matter collected by sediment traps in the Gulf of Finland (Baltic Sea), pp. 153-167. In: S. Floderus, A.-S. Heiskanen, M. Olesen and P. Wassmann (Eds.), Sediment trap studies in the nordic countries, Proc. Symp. No. 3.

Hilton, J., J.P. Lishman and P.V. Allen, 1986. The dominant processes of sediment distribution and focusing in a small, eutrophic, monomictic lake. Limnol. and Oceanogr. 31: $125-133$.

Honjo, S., 1982. Seasonality and interaction of biogenic and lithogenic particulate flux at the Panama Basin. Science 218:883-884.

Honjo, S. and K.W. Doherty, 1988. Large aperture time-series oceanic sediment traps: design objectives, construction and application. Deep-Sea Res. 35:133-149.

Honjo, S., J.F. Connell and P.L. Sachs, 1980. Deep-ocean sediment trap; design and function of PARFLUX Mark II. Deep-Sea Res. 27:745-753.

Imboden, D.M. and A. Wüest, 1995. Mixing mechanisms in lakes. In: Physics and Chemistry of Lakes (Eds.: A. Lerman, D.M. Imboden and J.R. Gat), pp. 83-137, Springer Heidelberg.

IOC Manual and Guides No. 29, 1994. Protocols for the Joint Global Ocean Flux Study (JGOFS) core measurements. UNESCO Scientific Committee on Oceanic Research.

Jannasch, H.W., O.C. Zafiriou and J.W. Farrington, 1980. A sequencing sediment trap for timeseries studies of fragile particles. Limnol. Oceanogr. 25:939-943.

Johnson, D.A., 1984. The Vema Channel: Physiography, structure, and sediment-current interactions. Mar. Geol. 58:1-34.

Johnson, R., G. Gust, W. Bowles, A. Michaels and A. Knap, 1991. Flows around surface-tethered sediment traps (Multitraps) at the U.S. JGOFS Bermuda Atlantic Time-series Station. The Oceanography Society Second Scientific Meeting March 24-28, 1991, St. Petersburg, Florida, U.S.A., Abstract volume, Abstract T2.Bt.05, p. 43.

Karl, D.M. and G.A. Knauer, 1989. Swimmers: a recapitulation of the problems and a potential solution. Oceanogr. Mag. 2:32-25.

Karl, D.M., G.A. Knauer and J.H. Martin, 1988. Downward flux of particulate organic matter in the ocean: a particle decomposition paradox. Nature 31:438-441.

Karl, D.M., J. R. Christian, J.E. Dore, D.V. Hebel, R.M. Letelier, L.M. Tupas and C.D. Winn, 1996. Seasonal and interannual variability in primary production and particle flux at Station ALOHA. Deep-Sea Res. II, 43:539-568.

Kelts, K. and K.J. Hsü, 1978. Freshwater carbonate sedimentation. pp. 295-323. In: Lerman, A. (Ed.), Lakes: Chemistry, Geology, Physics. Springer, New York. 
Knauer, G. A., J.H. Martingy and K.W. Bruland, 1979. Fluxes of particulate carbon, nitrogen, and phosphorus in the upper water column of the northeast Pacific (1979). Deep-Sea Res. 26:97-108.

Knauer, G. A., D.M. Karl, J.H. Martin and C.N. Hunter, 1984. In situ effects of selected preservatives on total carbon, nitrogen and metals collected in sediment traps. J. Mar. Res. 42:445-462.

Kozerski, H.-P., 1994. Possibilities and limitations of sediment traps to measure sedimentation and resuspension. Hydrobiologia 284:93-100.

Lau, Y.L., 1979. Laboratory study of cylindrical sedimentation traps. J. Fish. Res. Bd. Can. 36:1288-1291.

Lee, C., S.G. Wakeham and J.I. Hedges, 1988. The measurement of oceanic particle flux - are "swimmers" a problem? Oceanography 2:34-36.

Lee, C., J.I. Hedges, S.G. Wakeham and N. Zhu, 1992. Effectiveness of various treatments in retarding microbial activity in sediment trap material and their effects on the collection of swimmers. Limnol. Oceanogr. 37:117-130.

Lemmin, U. and D.M. Imboden, 1987. Dynamics of bottom currents in a small lake. Limnol. Oceanogr. 32:62-75.

Martin, J.H., G.A. Knauer, D.M. Karl and W.W. Broenkow, 1987. VERTEX: Carbon cycling in the northwest Pacific. Deep-Sea Res. 34:267-285.

Michaels, A.F., M.W. Silver, M.M. Gowing and G. A. Knauer, 1990. Cryptic zooplankton "swimmers" in the upper ocean sediment traps. Deep-Sea Res. 37:1285-1296.

Michaels, A.F., N.R. Bates, K.O. Buesseler, C.A. Carlson and A.H. Knap, 1994. Carbon-cycle imbalance in the Sargasso Sea. Nature 372:537-540.

Michaels, A.F. and A.H. Knap, 1996. Overview of the U.S. JGOFS Bermuda Atlantic Time-series Study and the Hydrostation S program. Deep-Sea Res. II, 43:157-198.

Murnane, R.J., J.K. Cochran, K.O. Buesseler and M.P. Bacon, 1996. Least-squares estimates of thorium, particle, and nutrient cycling rate constants from the JGOFS North Altlantic Bloom Experiment. Deep-Sea Res. I, 43:239-258.

Peck, R.M., 1972. Efficiency tests on the Tauber trap used as a pollen sampler in turbulent water flow. New Phytol. 71:187-198.

Peterson, M.L., P.J. Hernes, D.S. Thoreson and J.I. Hedges, 1993. Field evaluation of a valved sediment trap. Limnol. Oceanogr. 38:1741-1761.

Peterson, W. and H.G. Dam, 1990. The influence of copepod "swimmers" on pigment fluxes in brine-filled vs. ambient seawater-filled sediment traps. Limnol. Oceanogr. 35:448-455.

Prandtl, L., 1904. Über Flüssigkeitsbewegung bei sehr kleiner Reibung. Verhandl. III. Intern. Math. Kongr. Heidelberg, pp. 484-491.

Reynolds, C.S., 1984. The ecology of freshwater phytoplankton. Cambridge Studies in Ecology. Cambridge University Press.

Reynolds, C.S., S.W. Wiseman and W.D. Gardner, 1980. An annotated bibliography of aquatic sediment traps and trapping methods. Freshwater Biol. Assoc. Occas. Publ. 11.

Richardson, M.J. and C.D. Hollister, 1987. Compositional changes in particulate matter on the Iceland Rise, through the water column, and at the seafloor. J. Mar. Res. 45:175-200.

Rosa, F., J. Bloesch and D.E. Rathke, 1994. Sampling the settling and suspended particulate matter (SPM). Chapter 5, pp. 97-129. In: Mudroch, A. and MacKnight, S.D. (Eds.), Handbook of techniques for aquatic sediments sampling. 2nd ed., CRC Press, Boca Raton, Florida.

Santschi, P.H., 1989. Use of radionuclides in the study of contaminant cycling processes. Hydrobiologia 176/177:307-320.

Schwoerbel, J., 1994. Methoden der Hydrobiologie. Süsswasserbiologie. Gustav Fischer, Stuttgart und Jena, UTB Nr. 979, 4., neubearbeitete Auflage, 368 pp.

Shanks, A.L. and E.W. Edmondson, 1990. The vertical flux of metazoans (holoplankton, meiofauna, and larval invertebrates) due to their association with marine snow. Limnol. Oceanogr. 35:455-463.

Sigg, L., 1985. Metal transfer mechanisms in lakes; the role of settling particles. pp. 283-310. In: Stumm, W. (Ed.), Chemical Processes in Lakes. John Wiley \& Sons, New York.

Sigg, L., M. Sturm and D. Kistler, 1987. Vertical transport of heavy metals by settling particles in Lake Zürich. Limnol. Oceanogr. 32:112-130. 
Stabel, H.-H., 1985. Mechanisms controlling the sedimentation sequence of various elements in prealpine lakes. pp. 143-167. In: Stumm, W. (Ed.), Chemical Processes in Lakes. John Wiley \& Sons, New York.

Staresinic, N., K. von Bröckel, N. Smodlanka and C.H. Clifford, 1982. A comparison of moored and free-drifting sediment traps of two different designs. J. Mar. Res. 40:273-292.

Tooby, P.F., G.L. Wick and J.D. Isaacs, 1977. The motion of a small sphere in a rotating velocity field: A possible mechanism for suspending particles in turbulence. Journ. Geophys. Res. 82:2096-2100.

Urban, N.R., R. Gächter and J. Bloesch, 1996. The significance of C: N ratios in lacustrine particles. Limnol. Oceanogr., submitted.

U.S. GOFS Working Group. 1989. Sediment trap technology and sampling. Report No. 10. U.S. Global Ocean Flux Study, August 1989.

Vollenweider, R.A., 1974. A manual on methods for measuring primary production in aquatic environments. IBP Handbook No. 12, 2nd ed., Blackwell Sci. Publ., Oxford.

Wakeham, S.G., J.I. Hedges, C. Lee and T.K. Pease, 1993. Effects of poisons and preservatives on the composition of organic matter in a sediment trap experiment. J. Mar. Res. 51:669-696.

Walsh, I., K. Fischer, D. Murray and J. Dymond, 1988. Evidence for resuspension of rebound particles from near-bottom sediment traps. Deep-Sea Res. 35:59-70.

Wassmann, P., 1990. Relationship between primary and export production in the boreal coastal zone of the North Atlantic. Limnol. Oceanogr. 35:464-471.

Wassmann, P., 1991. Dynamics of primary production and sedimentation in shallow fjords and polls of western Norway. Oceanogr. Mar. Biol. Annu. Rev. 29:87-154.

Wei, Ch-L. and J.W. Murray, 1992. Temporal variations of ${ }^{234} \mathrm{Th}$ activity in the water column of Dabob Bay: Particle scavenging. Limnol. Oceanogr. 37:296-314.

Weyhenmeyer, G.A., 1996a. The influence of stratification on the amount and distribution of different settling particles in Lake Erken. Can. J. Fish. Aquat. Sci., in press.

Weyhenmeyer, G.A., 1996b. Quantification of resuspended particles in sedimentation traps. Verhandlungen Internat. Verein. theoret. angew. Limnol., in press.

Weyhenmeyer, G.A., M. Meili and D.C. Pierson, 1995. A simple method to quantify sources of settling particles in lakes: Resuspension versus new sedimentation of material from planktonic production. Marine and Freshwater Research 46:223-231.

Weyhenmeyer, L. Hakanson and G.A., M. Meili, 1996. A validated model for daily variations in the flux, origin and distribution of settling particles within lakes. Limnol. Oceanogr, submitted.

White, W.S. and R.G. Wetzel, 1973. A modified sedimentation trap. Limnol. Oceanogr. 18: 986-988.

Wieland, E., P.H. Santschi, P. Höhener and M. Sturm, 1993. Scavenging of Chernobyl ${ }^{137} \mathrm{Cs}$ and natural ${ }^{210} \mathrm{~Pb}$ in Lake Sempach, Switzerland. Geochimica et Cosmochimica Acta 57:29592979.

Zeitzschel, B., P. Diekmann and A. Uhlmann, 1978. A new multisample sediment trap. Mar. Biol. 45:285-288.

Invited: October 1996 